D. W. Dunstan · J. Salmon - N. Owen - T. Armstrong •

P. Z. Zimmet - T. A. Welborn - A. J. Cameron •

T. Dwyer $\cdot$ D. Jolley $\cdot$ J. E. Shaw $\cdot$ on behalf

of the AusDiab Steering Committee

\title{
Associations of TV viewing and physical activity with the metabolic syndrome in Australian adults
}

Received: 17 May 2005 / Accepted: 11 July 2005 / Published online: 7 October 2005

C) Springer-Verlag 2005

\begin{abstract}
Aims/hypothesis: We analysed a sample of Australian adults to determine the strength of associations of TV viewing and participation in physical activity with the metabolic syndrome. Methods: This population-based cross-sectional study included 6,241 adults aged $\geq 35$ years who were free from diagnosed diabetes mellitus and selfreported ischaemic disease and were not taking lipid-lowering or antihypertensive drugs. The metabolic syndrome was defined according to the 1999 World Health Orga-
\end{abstract}

D. W. Dunstan · P. Z. Zimmet · A. J. Cameron · J. E. Shaw International Diabetes Institute,

Melbourne, Victoria, Australia

J. Salmon · D. Jolley

School of Exercise and Nutrition Sciences, Deakin University, Melbourne, Victoria, Australia

N. Owen

Cancer Prevention Research Centre,

School of Population Health, The University of Queensland,

Brisbane, Queensland, Australia

T. Armstrong

Australian Institute of Health and Welfare,

Canberra, Australian Capital Territory, Australia

T. A. Welborn

Department of Medicine, The University of Western Australia,

Perth, Western Australia, Australia

T. A. Welborn

Department of Public Health

The University of Western Australia,

Perth, Western Australia, Australia

T. Dwyer

Menzies Centre for Population Health Research,

University of Tasmania,

Hobart, Tasmania, Australia

D. W. Dunstan $(\bowtie)$

International Diabetes Institute,

250 Kooyong Road,

Caulfield, Victoria 3162, Australia

e-mail: ddunstan@idi.org.au

Tel.: +61-3-92585050

Fax: $+61-3-92585090$ nization criteria. Participants self-reported TV viewing time and physical activity time for the previous week. Results: The adjusted odds ratio of having the metabolic syndrome was 2.07 (95\% CI 1.49-2.88) in women and $1.48(95 \%$ CI $0.95-2.31)$ in men who watched TV for $>14 \mathrm{~h}$ per week compared with those who watched $\leq 7.0 \mathrm{~h}$ per week. Compared with those who were less active $(<2.5 \mathrm{~h}$ per week), the odds ratio for the metabolic syndrome was $0.72(95 \%$ CI $0.58-0.90)$ in men and 0.53 (95\% CI $0.38-0.74)$ in women who were active $(\geq 2.5 \mathrm{~h}$ per week). Longer TV viewing ( $>14 \mathrm{~h}$ per week) was associated with an increased risk of insulin resistance, obesity and dyslipidaemia in both men and women. A total physical activity time of $\geq 2.5 \mathrm{~h}$ per week was associated with a reduced prevalence of both insulin resistance and dyslipidaemia in both sexes and reduced prevalence of both obesity and hypertension in women. Conclusions/ interpretation: Increased TV viewing time was associated with an increased prevalence of the metabolic syndrome, while physical activity was associated with a reduced prevalence. Population strategies addressing the metabolic syndrome should focus on reducing sedentary behaviours such as TV viewing, as well as increasing physical activity.

Keywords Glucose intolerance · Insulin resistance · Metabolic syndrome $\cdot$ Physical activity $\cdot$ Sedentary behaviour · Obesity

Abbreviations AusDiab: Australian Diabetes, Obesity and Lifestyle Study - CVD: cardiovascular disease · IDF: International Diabetes Federation . NCEP: National Cholesterol Education Program . WHO: World Health Organization

\section{Introduction}

Physical inactivity is associated with a greater risk of cardiovascular disease (CVD) [1] and type 2 diabetes [2]. Recognition of the importance of physical activity has increased in the face of the epidemics of sedentary lifestyle, 
obesity and the associated metabolic syndrome. The metabolic syndrome provides a unifying aetiological framework for the development of CVD, hypertension, dyslipidaemia and glucose intolerance [3]. While epidemiological studies show that physical activity and cardiovascular fitness reduce the risk of many of the features of the metabolic syndrome, in many studies, the lack of standard definitions of the metabolic syndrome and its components has hampered efforts to interpret the relationships with physical activity [4-8].

Sedentary behaviour, especially TV viewing, is positively associated with an increased risk of obesity and CHD risk factors $[9,10]$. 'Sedentariness' and physical activity are two distinct classes of behaviour that have different patterns of determinants [11]. They are likely to have independent effects on total energy expenditure, weight and metabolic variables $[12,13]$. To date, no large population-based studies have assessed simultaneously the associations of TV viewing and physical activity with the metabolic syndrome. In addition, there is little information on the extent to which sedentary behaviour and physical activity influence components of the metabolic syndrome other than obesity. We examined the cross-sectional associations of TV viewing time and physical activity with the presence of the metabolic syndrome [as defined by the World Health Organization (WHO)] [3] in a populationbased sample of Australian adults. We also examined the extent to which obesity mediates the relationships of TV viewing time and physical activity time with the other components of the metabolic syndrome.

\section{Subjects and methods}

The 1999-2000 Australian Diabetes, Obesity and Lifestyle Study (AusDiab) gathered data from a representative sample of 11,247 adults [14-16]. This represented $55 \%$ of those who completed an initial household interview. Insulin assays were conducted only for the population aged $>35$ years $(n=9,644)$. The present analyses use data from adults aged $>35$ years with complete data for all components of the metabolic syndrome and TV viewing time and physical activity time $(n=7,821)$. We excluded those who were pregnant and those with health conditions affecting physical activity, including clinically diagnosed type 2 diabetes, selfreported angina, stroke and myocardial infarction, and those taking medications for hypertension or dyslipidaemia. Thus, the final study population included 6,162 adults

Table 1 Selected characteristics of the 6,162 adults aged $>35$ years in the AusDiab according to the presence of the metabolic syndrome

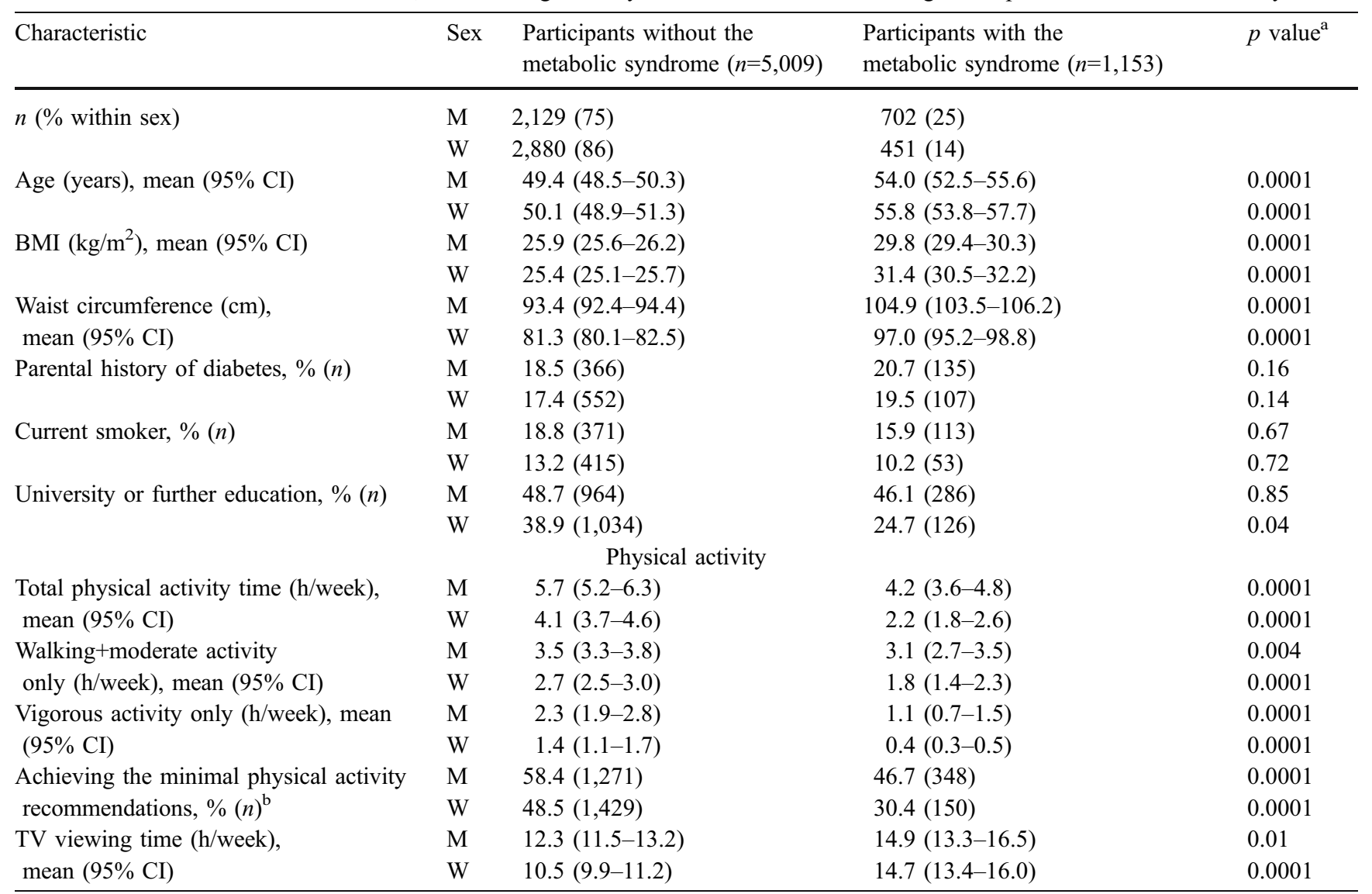

The data are weighted to the Australian population and are presented as unadjusted means or percentages

$M$ Men, $W$ women

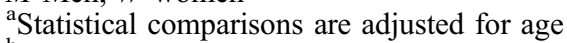

${ }^{\mathrm{b}}$ Based on the recommended public health guidelines for physical activity ( $\geq 2.5 \mathrm{~h}$ per week) [22, 23] 
(2,831 men and 3,331 women). The study was approved by the Ethics Committee of the International Diabetes Institute. Written informed consent was obtained from all participants.

Participants attended the local survey centre after an overnight fast $(>8 \mathrm{~h})$. The measurement procedures (for waist circumference, height, weight and $\mathrm{BP}$ ) and relevant criteria used have been described in earlier publications $[14,15]$. Using the 1999 WHO criteria [3], participants were defined as having the metabolic syndrome if they had insulin resistance (fasting insulin levels in the upper quartile of the non-diabetic population), IGT (fasting plasma glucose $<7.0 \mathrm{mmol} / \mathrm{l}$ and 2 -h plasma glucose $\geq 7.8 \mathrm{but}$ $<11.1 \mathrm{mmol} / \mathrm{l}$ ) or diabetes (fasting plasma glucose $\geq 7.0 \mathrm{mmol} /$ 1 or 2 -h plasma glucose $\geq 11.1 \mathrm{mmol} / \mathrm{l}$ ) on the glucose tolerance test and at least two of the following: (1) obesity (WHR $>0.90$ for men or $>0.85$ for women, or BMI $>30 \mathrm{~kg} / \mathrm{m}^{2}$ ); (2) dyslipidaemia (serum triglycerides $\geq 1.7 \mathrm{mmol} / 1$ or HDL cholesterol $<0.9 \mathrm{mmol} / 1$ for men or $<1.0 \mathrm{mmol} / 1$ for women); (3) hypertension ( $\mathrm{BP} \geq 140 / 90 \mathrm{~mm} \mathrm{Hg}$ or antihypertensive medication); and (4) microalbuminuria (urinary albumin/ creatinine ratio $\geq 2.5 \mathrm{mg} / \mathrm{mmol}$ in men or $\geq 3.5 \mathrm{mg} / \mathrm{mmol}$ in women). For comparative purposes, the metabolic syndrome criteria of the National Cholesterol Education Program (NCEP) Expert Panel [17] and the recent International Diabetes Federation (IDF) definition [18] were also applied.

Demographic attributes, parental history of diabetes, smoking habits and educational attainment were assessed using an interviewer-administered questionnaire. Dietary intake was assessed using a self-administered validated foodfrequency questionnaire [19]. Calculation of nutrient intake was achieved by multiplying the frequency of food consumption by standard portion weights. These were then converted into nutrient intakes based on the NUTTAB95 nutrient composition data [20].

Participants reported total time spent watching TV or videos in the previous week, using a validated instrument [21]. The total time spent watching TV per week was used to create three categories of TV viewing $(0-7,7.01-14$ and $>14 \mathrm{~h}$ per week). The validated Active Australia Survey uestionnaire [22] was used to ascertain participants' frequency and duration of physical activity during the previous week. This includes items about walking for recreation or transport, 'other' moderate activity and vigorous activity. Total physical activity time was calculated as the sum of the time spent walking (if continuous and $\geq 10 \mathrm{~min}$ ), the time spent doing other moderate-intensity activities, plus double the time spent participating in vigorous physical activity. The 'Active Australia' method accounts for the higher volume of energy expenditure per unit time that is associated with vigorous activities [22]. As vigorous-intensity physical activity contributes additional benefits to health [23], we analysed associations of the metabolic syndrome with walking plus moderate physical activity time (excluding those who reported any vigorous activity: men $32 \%$, women $27 \%$ ) and with vigorous physical activity only (excluding those who reported any walking plus moderate physical activity: men $80 \%$, women $78 \%$ ). Total physical activity cate-

Table 2 Adjusted odds ratios for the presence of the metabolic syndrome according to categories of TV viewing time and physical activity in men and women

\begin{tabular}{|c|c|c|c|c|c|c|}
\hline \multirow[t]{2}{*}{ Category } & \multicolumn{3}{|l|}{ Men } & \multicolumn{3}{|l|}{ Women } \\
\hline & Number & $\begin{array}{l}\text { Age-adjusted OR } \\
(95 \% \mathrm{CI})\end{array}$ & $\begin{array}{l}\text { Multivariate } \mathrm{OR}^{\mathrm{a}} \\
(95 \% \mathrm{CI})\end{array}$ & Number & $\begin{array}{l}\text { Age-adjusted OR } \\
(95 \% \mathrm{CI})\end{array}$ & $\begin{array}{l}\text { Multivariate } \mathrm{OR}^{\mathrm{a}} \\
(95 \% \mathrm{CI})\end{array}$ \\
\hline \multicolumn{7}{|c|}{ TV viewing time (h/week) } \\
\hline$\leq 7$ & 843 & 1.00 & 1.00 & 1,296 & 1.00 & 1.00 \\
\hline $7-14$ & 963 & $1.21(0.84-1.75)$ & $1.17(0.77-1.76)$ & 1,066 & $1.09(0.69-1.72)$ & $1.17(0.78-1.76)$ \\
\hline$>14$ & 1,025 & $1.64(1.11-2.42)$ & $1.48(0.95-2.31)$ & 969 & $2.16(1.48-3.15)$ & $2.07(1.49-2.88)$ \\
\hline$p$ value for trend & & 0.02 & 0.07 & & 0.0001 & 0.0001 \\
\hline \multicolumn{7}{|c|}{ Total physical activity (h/week) } \\
\hline$<2.5$ & 1,212 & 1.00 & 1.00 & 1,752 & 1.00 & 1.00 \\
\hline$\geq 2.5$ & 1,619 & $0.61(0.51-0.73)$ & $0.72(0.58-0.90)$ & 1,579 & $0.46(0.32-0.66)$ & $0.53(0.38-0.74)$ \\
\hline$p$ value for trend & & 0.0001 & 0.004 & & 0.0001 & 0.0001 \\
\hline \multicolumn{7}{|c|}{ Walking + moderate physical activity only $\left(\mathrm{h}\right.$ per week) ${ }^{\mathrm{b}}$} \\
\hline$<2.5$ & 1,121 & 1.00 & 1.00 & 1,624 & 1.00 & 1.00 \\
\hline$\geq 2.5$ & 772 & $0.89(0.74-1.08)$ & $1.03(0.83-1.29)$ & 837 & $0.56(0.36-0.87)$ & $0.62(0.41-0.95)$ \\
\hline$p$ value for trend & & 0.22 & 0.78 & & 0.01 & 0.03 \\
\hline \multicolumn{7}{|c|}{ Vigorous physical activity only $(\mathrm{h} / \text { week })^{\mathrm{c}}$} \\
\hline$<1$ & 457 & 1.00 & 1.00 & 625 & 1.00 & 1.00 \\
\hline$\geq 1$ & 115 & $0.52(0.24-1.12)$ & $0.56(0.29-1.08)$ & 122 & $0.26(0.11-0.62)$ & $0.32(0.13-0.78)$ \\
\hline$p$ value for trend & & 0.09 & 0.08 & & 0.003 & 0.014 \\
\hline
\end{tabular}

$O R$ Odds ratio

${ }^{\mathrm{a}}$ Variables included in the model were age, education, family history of diabetes, cigarette smoking, dietary covariates (total energy, total fat, total saturated fat, total carbohydrate, total sugars, fibre, alcohol) and total physical activity/TV viewing time

${ }^{\mathrm{b}}$ Only those who reported no vigorous activity were included in the walking+moderate physical activity only analyses

${ }^{\mathrm{c}}$ Only those who reported no walking+moderate physical activity were included in the vigorous activity analyses 
gories were created to reflect current recommendations: those meeting the current public health physical activity guidelines ( $\geq 2.5 \mathrm{~h}$ per week) and those not meeting the public health guidelines $(0-2.49 \mathrm{~h}$ per week). Participants were classified as meeting the public health guidelines through walking plus moderate-intensity physical activity only ( $\geq 2.5 \mathrm{~h}$ per week), through vigorous activity only $(\geq 1.0 \mathrm{~h}$ per week) or as not meeting these guidelines.

Statistical analysis Statistical analyses were conducted using STATA Statistical Software Package, Release 8.0 (STATA, College Station, TX, USA) survey commands for analysing complex survey data. Sample weights based on the 1998 estimated residential Australian population aged $>35$ years were used to account for clustering and stratification in the survey design and for non-response. Odds ratios (with 95\% CI) for binary outcomes were estimated using forced entry logistic regression models. Regression models included the TV viewing and physical activity categories and were adjusted for age, education level, cig- arette smoking, parental history of diabetes and dietary covariates. We used a further logistic regression model to test for interactions of TV viewing time and total physical activity time with the risk of the metabolic syndrome individually by sex and adjusted for the same covariates. A $p$ value of less than 0.05 was considered significant. To examine the extent to which obesity may mediate associations of TV viewing and physical activity with the components of the metabolic syndrome, two regression models were applied, both with and without obesity included as a covariate.

\section{Results}

Table 1 shows that the prevalence of the metabolic syndrome was $25 \%$ in men and $14 \%$ in women. Participants with the metabolic syndrome were older, spent more time watching TV and were significantly less active than participants without the metabolic syndrome.

Table 3 Adjusted odds ratios for the presence of metabolic syndrome components according to categories of TV viewing and total physical activity

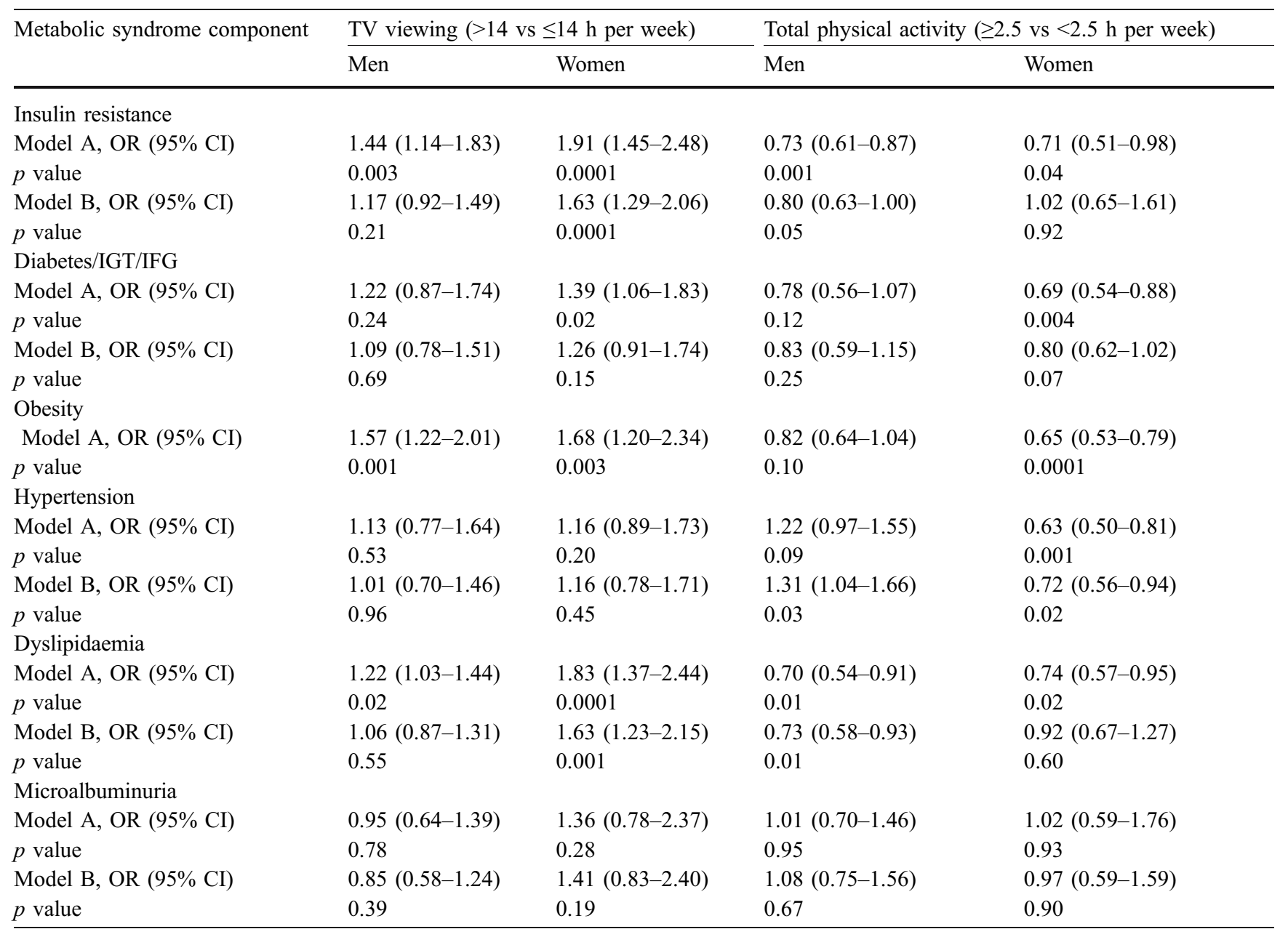

Model A: adjusted for age, education, family history of diabetes, cigarette smoking, dietary covariates (total energy, total fat, total saturated fat, total carbohydrate, total sugars, fibre, alcohol), TV viewing time/physical activity time

Model B: adjusted for all covariates plus waist circumference

$O R$ Odds ratio 
Table 2 shows that associations between the metabolic syndrome and TV viewing categories were stronger in women than in men, and that, in women, these associations were independent of all other factors. Similar findings for the associations with TV viewing were obtained using alternative metabolic syndrome criteria (NCEP and IDF; results not shown). The prevalence of the metabolic syndrome was inversely related to total physical activity time in both sexes, with the association being stronger in women (Table 2), and independent of other factors for both sexes. Women who did not undertake any vigorous activity, but who still achieved the public health physical activity target of $\geq 2.5 \mathrm{~h}$ per week through walking and moderate physical activity, were significantly less likely to have the metabolic syndrome than those women who did not achieve the physical activity target. However, for men, this level of moderate-intensity physical activity was not associated with any protection from the metabolic syndrome. A significant inverse association with the metabolic syndrome was observed in women and approached statistical significance in men $(p=0.09)$ for those who did not undertake any walking or moderate physical activity but who participated in $\geq 1 \mathrm{~h}$ per week of vigorous activity compared with those who engaged in $<1 \mathrm{~h}$ per week of vigorous activity only. In models adjusted for all other covariates (model B), analyses using the NCEP and IDF definitions of the metabolic syndrome in women showed similar significant inverse associations for total physical activity and walking plus moderate activity, but no association for vigorous activity (results not shown). No significant associations with any of the activity categories were observed in men for either the NCEP or IDF definitions.

After adjustment for all other covariates listed in Table 2, for each 1-h increase in TV viewing time per day, there was a $12 \%(95 \%$ CI $-0.01-27 \% ; p=0.07)$ and $26 \%(95 \%$ CI $14-46 \%$; $p=0.0001)$ increase in the prevalence of the metabolic syndrome in men and women, respectively. Each 30min increase in physical activity per day was associated with an $11 \%$ (95\% CI 6-17\%; $p=0.001)$ and $28 \%(95 \%$ CI $16-39 \% ; p=0.0001)$ decrease in the prevalence of the metabolic syndrome in men and women, respectively.

For both sexes, participants watching $>14 \mathrm{~h}$ of TV per week were more likely to have insulin resistance, obesity and dyslipidaemia, but not hypertension, compared with those watching $<14 \mathrm{~h}$ per week (Table 3 ). A higher TV viewing time was also associated with diabetes/IGT/IFG in women only. Waist circumference had a mediating effect on the relationships between TV viewing time and components of the metabolic syndrome (model B); however, in women only, the associations between TV viewing time and insulin resistance and dyslipidaemia remained significant after adjustment for waist circumference. Subjects who reported $\geq 2.5 \mathrm{~h}$ total physical activity per week had a reduced prevalence of both insulin resistance and dyslipidaemia. Women who met the physical activity guidelines were also less likely to have diabetes/IGT/IFG, obesity and hypertension. The associations between total physical activity and hypertension in women and dyslipidaemia in men were partially mediated by waist circumference, but

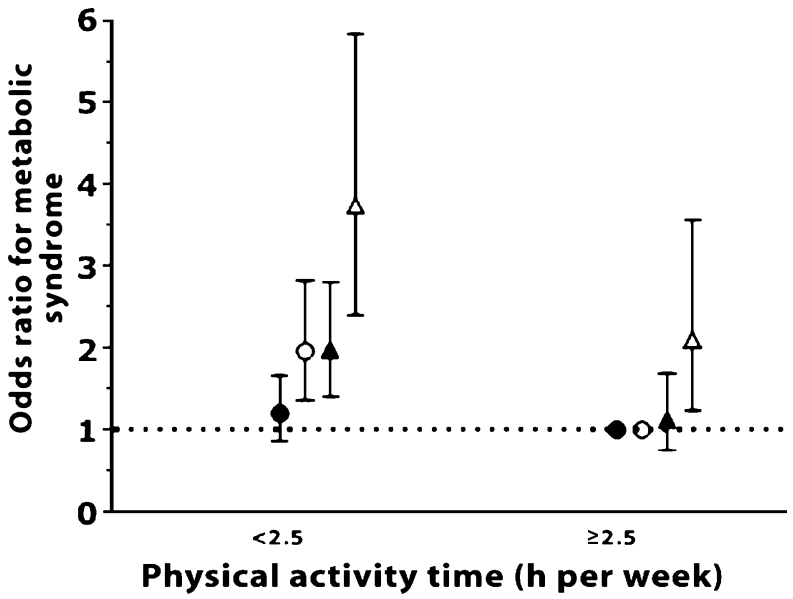

Fig. 1 Adjusted odds ratio for presence of the metabolic syndrome (95\% CI) according to level of physical activity and TV viewing time (adjusted for age, sex, education, smoking, parental history of diabetes and dietary covariates). TV viewing time $\leq 14 \mathrm{~h}$ per week: men closed circles, women open circles; TV viewing time $>14$ h per week: men closed triangles, women open triangles

remained significant after adjustment for this variable. A positive association between total physical activity and hypertension was also observed in men following adjustment for waist circumference. No associations were observed with microalbuminuria.

Figure 1 shows the relationship between TV viewing time and the metabolic syndrome across the two categories of physical activity. The interaction term between TV viewing time and total physical activity time approached significance in men only $(p=0.09)$. Compared with those who reported both $\geq 2.5 \mathrm{~h}$ physical activity per week and a TV viewing time of $\leq 14 \mathrm{~h}$ per week, women who were not sufficiently active $(<2.5 \mathrm{~h}$ per week) had a significantly increased prevalence of the metabolic syndrome, irrespective of their level of TV viewing time, while men reporting $<2.5 \mathrm{~h}$ physical activity per week only had an increased prevalence of the metabolic syndrome if they also watched TV for $>14 \mathrm{~h}$ per week. Furthermore, women who were physically active but watched TV for $>14 \mathrm{~h}$ per week had an increased prevalence of the metabolic syndrome compared with those who were active but watched less TV.

\section{Discussion}

In this large cross-sectional study of Australian adults, spending time being sedentary was associated with an increased prevalence of the metabolic syndrome, independently of physical activity time. A higher TV viewing time was also associated with all of the components of the metabolic syndrome, with the exceptions of hypertension and microalbuminuria, while compliance with the recommended public health guidelines for physical activity $(\geq 2.5 \mathrm{~h}$ per week) was associated with a reduced prevalence of several components of the metabolic syndrome. 
The positive association observed between TV viewing and the metabolic syndrome is consistent with that observed in the Bogalusa Heart Study [7] and confirms other reports of an inverse association between physical activity and the risk of the metabolic syndrome [4-6, 8], and of associations between physical activity and several components of the metabolic syndrome [4, 6, 8-10, 24]. The present findings are also consistent with another population-based cohort study of 612 middle-aged men from Finland [4], which demonstrated that men who reported $>3 \mathrm{~h}$ of structured or lifestyle physical activity per week were half as likely to develop the metabolic syndrome after 4 years as those who were sedentary ( $<60$ min per week).

It has been suggested that $\mathrm{TV}$ viewing displaces physical activity and is thus a surrogate measure of reduced total energy expenditure [25]. However, TV viewing time and physical activity time, as measured by questionnaire, were not closely related in our study or in other studies [13]. Furthermore, the positive association between TV viewing time and prevalence of the metabolic syndrome was independent of physical activity. TV viewing may also be associated with poorer eating habits, particularly snacking behaviour [26], although the current study showed that the association between TV viewing time and the metabolic syndrome was independent of overall dietary intake. Recently, it has been postulated that some proteins, such as lipoprotein lipase, may be regulated by qualitatively different processes across the physical activity continuum, sometimes with a very high sensitivity to inactivity [27]. This proposes the existence of underlying physiological mechanisms that may support the concept of independent metabolic health effects of sedentary time (as indicated by TV viewing time).

We found that the relationships of TV viewing time with insulin resistance and dyslipidaemia in men were mediated by waist circumference. In contrast, associations with insulin resistance and dyslipidaemia in women remained significant after adjustment for waist circumference, suggesting that mechanisms other than central obesity may contribute to an increased risk in some of the key components of the metabolic syndrome in women who watch TV for long periods.

A positive association between physical activity and the prevalence of hypertension in men, following adjustment for waist circumference, was an unexpected finding, particularly since other cross-sectional studies have indicated that physical activity is inversely associated with BP [10, 28]. Prospective studies using clinically measured BP have demonstrated that physical activity reduces the risk of hypertension $[29,30]$. Our findings are consistent with a recent cross-sectional study in young adults (25-45 years) from Israel [31], which reported a positive association between physical activity levels and hypertension in men and a non-significant inverse association in women.

In general, we found stronger associations with the metabolic syndrome and its components in women for both TV viewing time and physical activity time. Interestingly, it has been found that women report physical activity more accurately than men [32]. Our findings may also be related to limitations in the physical activity instrument, which excludes assessment of domestic and occupational physical activity. It is plausible that within everyday activities (e.g. household chores and work activity), many women spend more time in light/moderate physical activity, whereas men spend more time in vigorous activity. This is supported by our observation that although total physical activity (which also includes vigorous activity) was inversely associated with the metabolic syndrome in men, there was no association when vigorous activity was excluded.

The results also showed that, when walking and moderate physical activity were excluded, the reduction in risk of the metabolic syndrome (in relation to vigorous activity) was more pronounced in women than men. A greater attenuation of the physical activity effect in men following adjustment for the full set of covariates could also indicate that these covariates are either not as prevalent or are less important in women. Women may participate more extensively in other sedentary behaviours, which might also explain why the relationships between physical activity/TV viewing time and the metabolic syndrome and its components were stronger in this group. Furthermore, previous research has demonstrated that a higher proportion of women underreport their dietary intake [33], which could also explain the stronger associations observed between TV viewing time and the metabolic syndrome in women, even after adjusting for dietary intake.

The strengths of this study are its large sample size across a wide age range and objective data for all of the components of the WHO definition of the metabolic syndrome. Its limitations include assessment of just one aspect of sedentary living (TV viewing time) and the cross-sectional study design. Therefore, it is difficult to determine the extent to which participants were in lower physical activity or higher TV viewing time categories because of their health status; however, the exclusion of participants with known diabetes, hypertension, dyslipidaemia and symptomatic CVD should have limited the effect of health status on physical activity time and TV viewing time. Longitudinal studies in this population should clarify the temporal associations between TV viewing time, physical activity time and the metabolic syndrome. Future research should also aim to collect objective physical activity data using, for example, accelerometers or pedometers.

In conclusion, we found that prolonged TV viewing is significantly associated with an increased prevalence of the metabolic syndrome and several of its components, while meeting current public health guidelines for physical activity is associated with a reduced prevalence. Furthermore, the relationships between of these health behaviours with components of the metabolic syndrome were only partially mediated by weight status. The study also showed that the positive association between TV viewing time and the metabolic syndrome was more pronounced in women.

Our findings suggest that, in order to reduce the prevalence of the metabolic syndrome and its components, it may not only be important to increase participation in physical activity, but also to reduce time spent watching TV (and possibly other sedentary behaviours). 
Acknowledgements The following provided financial support for the study: The Commonwealth Department of Health and Aged Care, Abbott Australasia, Alphapharm, Aventis Pharmaceutical, AstraZeneca, Bristol-Myers Squibb Pharmaceuticals, Eli Lilly (Australia), GlaxoSmithKline, Janssen-Cilag (Australia), Merck Lipha, Merck Sharp \& Dohme (Australia), Novartis Pharmaceutical (Australia), Novo Nordisk Pharmaceutical, Pharmacia and Upjohn, Pfizer, Roche Diagnostics, Sanofi Synthelabo (Australia), Servier Laboratories (Australia), BioRad Laboratories, HITECH Pathology, the Australian Kidney Foundation, Diabetes Australia, Diabetes Australia (Northern Territory), Queensland Health, South Australian Department of Human Services, Tasmanian Department of Health and Human Services, Territory Health Services, Victorian Department of Human Services and Health Department of Western Australia. D. Dunstan is supported by a National Health and Medical Research Council (NHMRC) Post-Doctoral Research Fellowship. J. Salmon is supported by a Victorian Health Promotion Foundation Public Health Research Fellowship. N. Owen's participation was made possible by the support of Queensland Health and by Program Grant funding from the NHMRC. For their invaluable contribution to the field activities of AusDiab, we are enormously grateful to A. Allman, M. Dalton, A. Meehan, C. Reid, A. Stewart, R. Tapp and F. Wilson. The AusDiab Steering Committee consists of B. Atkins, S. Bennett, S. Chadban, S. Colagiuri, M. de Courten, M. D'Embden, D. Dunstan, T. Dwyer, D. Jolley, P. Magnus, J. Mathews, D. McCarty, K. O'Dea, P. Phillips, P. Popplewell, I. Kemp, H. Taylor, T. Welborn and P. Zimmet.

\section{References}

1. Wannamethee SG, Shaper AG, Walker M, Ebrahim S (1998) Lifestyle and 15-year survival free of heart attack, stroke, and diabetes in middle-aged British men. Arch Intern Med 158:24332440

2. Helmrich SP, Ragland DR, Leung RW, Paffenbarger RS (1991) Physical activity and reduced occurrence of non-insulin-dependent diabetes mellitus. New Engl J Med 325:147-152

3. World Health Organization (1999) Definition, diagnosis and classification of diabetes mellitus and its complications. World Health Organization, Geneva

4. Laaksonen DE, Lakka HM, Salonen JT, Niskanen LK, Rauramaa R, Lakka TA (2002) Low levels of leisure-time physical activity and cardiorespiratory fitness predict development of the metabolic syndrome. Diabetes Care 25:1612-1618

5. Wareham NJ, Hennings SJ, Byrne CD, Hales CN, Prentice AM, Day NE (1998) A quantitative analysis of the relationship between habitual energy expenditure, fitness and the metabolic cardiovascular syndrome. Br J Nutr 80:235-241

6. Rennie KL, McCarthy N, Yazdgerdi S, Marmot M, Brunner E (2003) Association of the metabolic syndrome with both vigorous and moderate physical activity. Int J Epidemiol 32:600-606

7. Gustat J, Srinivasan SR, Elkasabany A, Berenson GS (2002) Relation of self-rated measures of physical activity to multiple risk factors of insulin resistance syndrome in young adults: the Bogalusa Heart Study. J Clin Epidemiol 55:997-1006

8. Lakka TA, Laaksonen DE, Lakka HM et al (2003) Sedentary lifestyle, poor cardiorespiratory fitness, and the metabolic syndrome. Med Sci Sports Exerc 35:1279-1286

9. Kronenberg F, Pereira MA, Schmitz MK et al (2000) Influence of leisure time physical activity and television watching on atherosclerosis risk factors in the NHLBI Family Heart Study. Atherosclerosis 153:433-443

10. Jakes RW, Day NE, Khaw KT et al (2003) Television viewing and low participation in vigorous recreation are independently associated with obesity and markers of cardiovascular disease risk: EPIC-Norfolk population-based study. Eur J Clin Nutr 57:1089-1096

11. Owen N, Leslie E, Salmon J, Fotheringham MJ (2000) Environmental determinants of physical activity and sedentary behavior. Exerc Sport Sci Rev 28:153-158
12. Hu FB, Leitzmann MF, Stampfer MJ, Colditz GA, Willett WC, Rimm EB (2001) Physical activity and television watching in relation to risk for type 2 diabetes mellitus in men. Arch Intern Med 161:1542-1548

13. Hu FB, Li TY, Colditz GA, Willett WC, Manson JE (2003) Television watching and other sedentary behaviors in relation to risk of obesity and type 2 diabetes mellitus in women. J Am Med Assoc 289:1785-1791

14. Dunstan DW, Zimmet PZ, Welborn TA et al (2002) The Australian Diabetes, Obesity and Lifestyle Study (AusDiab) methods and response rates. Diabetes Res Clin Pract 57:119 129

15. Dunstan DW, Zimmet PZ, Welborn TA et al (2002) The rising prevalence of diabetes and impaired glucose tolerance: the Australian Diabetes, Obesity and Lifestyle Study. Diabetes Care 25:829-834

16. Cameron AJ, Welborn TA, Zimmet PZ et al (2003) Overweight and obesity in Australia: the 1999-2000 Australian Diabetes, Obesity and Lifestyle Study (AusDiab). Med J Aust 178:427432

17. National Cholesterol Education Program (2001) Executive summary of the third report of the National Cholesterol Education Program (NCEP) Expert Panel on detection, evaluation, and treatment of high blood cholesterol in adults (Adult Treatment Panel III). J Am Med Assoc 285:2486-2497

18. International Diabetes Federation (2005) The IDF consensus worldwide definition of the metabolic syndrome. Available from http://www.idf.org/webdata/docs/Metabolic_syndrome_definition. pdf, accessed 5 May 2005

19. Ireland P, Jolley D, Giles G et al (1994) Development of the Melbourne FFQ: a food frequency questionnaire for use in an Australian prospective study involving an ethnically diverse cohort. Asia Pac J Clin Nutr 3:19-31

20. Lewis J, Milligan G, Hunt A (1995) NUTTAB95 nutrient data table for use in Australia. Australian Government Publishing Service, Canberra

21. Salmon J, Owen N, Crawford D, Bauman A, Sallis JF (2003) Physical activity and sedentary behavior: a population-based study of barriers, enjoyment, and preference. Health Psychol 22:178-188

22. Australian Institute of Health and Welfare (2003) The Active Australia Survey. A guide and manual for implementation, analysis and reporting. AIHW, Canberra

23. US Department of Health and Human Services (1996) Physical activity and health: a report of the Surgeon General. Centers for Disease Control and Prevention, National Center for Chronic Disease Prevention and Health Promotion, Washington

24. Fung TT, Hu FB, Yu J et al (2000) Leisure-time physical activity, television watching, and plasma biomarkers of obesity and cardiovascular disease risk. Am J Epidemiol 152:11711178

25. Ching PL, Willett WC, Rimm EB, Colditz GA, Gortmaker SL, Stampfer MJ (1996) Activity level and risk of overweight in male health professionals. Am J Public Health 86:25-30

26. Jeffery RW, French SA (1998) Epidemic obesity in the United States: are fast foods and television viewing contributing? Am J Public Health 88:277-280

27. Hamilton M, Hamilton D, Zderic T (2004) Exercise physiology versus inactivity physiology: an essential concept for understanding lipoprotein lipase regulation. Exerc Sport Sci Rev 32:161-166

28. Hu G, Pekkarinen H, Hanninen O, Tian H, Jin R (2002) Comparison of dietary and non-dietary risk factors in overweight and normal-weight Chinese adults. Br J Nutr 88:91-97

29. Pereira MA, Folsom AR, McGovern PG, et al (1999) Physical activity and incident hypertension in black and white adults: the Atherosclerosis Risk in Communities Study. Prev Med 28:304 312

30. Bassett DR Jr, Fitzhugh EC, Crespo CJ, King GA, McLaughlin JE (2002) Physical activity and ethnic differences in hypertension prevalence in the United States. Prev Med 34:179-186 
31. Sharabi Y, Grotto I, Huerta M, Grossman E (2004) Susceptibility of the influence of weight on blood pressure in men versus women: lessons from a large-scale study of young adults. Am J Hypertens 17:404-408

32. Timperio A, Salmon J, Bull F, Rosenberg M (2002) Validation of physical activity questions for use in Australian population surveys. Commonwealth Department of Aging, Canberra
33. Briefel RR, Sempos CT, McDowell MA, Chien S, Alaimo K (1997) Dietary methods research in the third National Health and Nutrition Examination Survey: underreporting of energy intake. Am J Clin Nutr 65:1203S-1209S 